\title{
Studies on ampicillin resistant plasmid of Streptococcus mutans isolated from dental caries patients
}

\author{
S. Karikalan and A. Mohankumar* \\ Division of Microbial Technology, Post Graduate Research Department of Zoology, Chikkanna Government \\ Arts College, Tirupur - 641 602, Tamilnadu, India
}

\begin{abstract}
Dental caries is a well known major oral health problem in most countries. The multifactorial etiology of the disease includes multiple bacterial species, S. mutans is the main pathogen associated with the disease. Streptococcus mutans is recognized as the main pathogen of dental caries in human beings. One of the important virulence properties of $S$. mutans is their ability to form biofilms on tooth surfaces which make them a primary an etiological agent in dental caries. This bacterium allows the colonization of other microorganisms resulting in dental plaque. Recently multi drug resistant species of $S$. mutans were identified from the dental caries patients against many commercial antibiotics. Several therapeutic agents are available to treat or prevent tooth decay, but none of them showed complete sensitivity and have significantly influenced the disease's global burden. Totally, fifty extracted tooth samples with chronic dental caries were selected for this study. The effectivity of caries was determined by the caries susceptibility test. S. mutans, the predominant cariogens were isolated from dental caries patients. Ten antibiotics (Penicillin-G, Ampicillin, Cefaclor, Tetracycline, Erythromycin, Chloramphenicol, Ciprofloxacin, Amoxicillin, Vancomycin and Kanamycin) were used for antibiotic susceptibility test, among Ampicillin showed 70\% resistant proved against to the strains of S.mutans. The plasmid of the isolates has specific antibiotic resistance against antibiotics like ampicillin and it has cell wall breaking capacity. R-plasmid (Resistant plasmid) was obtained from Ampicillin resistant strains of $S$. mutans from extracted tooth samples of dental caries disease. The molecular weight of the isolates were (KK2, 3 and KK4, 5) 800bp and 700bp respectively.
\end{abstract}

KEY WORDS: DENTAL CARIES, STREPTOCOCCUS MUTANS, ANTIBIOTIC SUSCEPTIBILITY, R- PLASMID

\section{INTRODUCTION}

Dental caries and periodontal diseases are the leading cause of tooth loss, and while dental caries leads to odontogenic infections, which may be primary or secondary to periodontal, pericoronal, traumatic or postsurgical infections. Dental plaque is an organized mass of bacteria already present in the oral cavity, on the surface

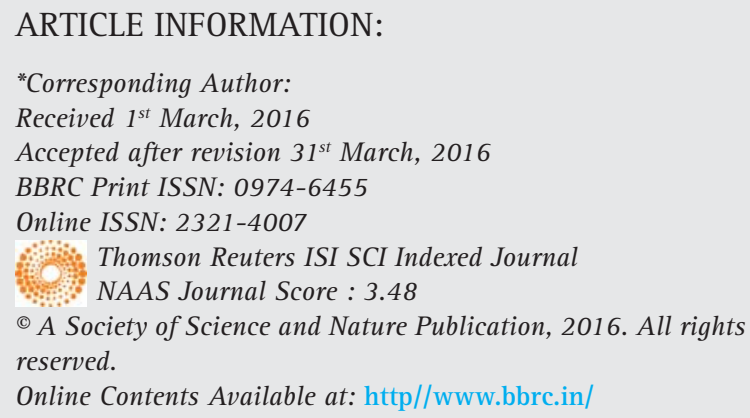


of the teeth as a result of their accumulation in the face of poor oral hygiene and poor diet. Caries result when bacteria in the plaque, via a process called fermentation, break down carbohydrate for their energy requirement and produce end products, such as acids, including lactic acid, which causes the $p \mathrm{H}$ of plaque to fall in a matter of few minutes to 4.0 to 4.5 , thus overcoming the saturation of the saliva and plaque with calcium and phosphate, and demineralization occurs.

The understanding of mechanisms involved in the formation, virulence and drug resistance of dental biofilms is very important and have showed the importance of dental caries disease, a critical disease to human beings. Streptococcus mutans is commonly found in the human oral cavity, is a significant contributor to tooth decay and has the ability to cause bacteria endocarditis. It is a member of the viridans Streptococci and occurs in chains. The mixture of organisms regularly found at any anatomical site is referred to as the normal flora. At about 6-9 months, with the appearance of the teeth, the oral cavity becomes colonized by Streptococcus mutans, and Streptococcus sanguis and they stay as long as the teeth remain, (Ash et al., 1986, Loesche, 1996, Patterson, 1996, Wagman, 2000, Ryan et al., 2004, Da Silva et al., 2014).

The conventional antibiotic therapy is effective in treating bacterial infections. However, with increasing antibiotic resistance, there is a need for newer approaches in the management of these infections. In recent years, some isolates of S.mutans have begun to show considerable resistance to commonly used antibiotics. The characterization of these drug resistant isolates and their heterogeneity studies may provide more information on their genetic makeup and also be useful in the management and control of drug resistance to at least that region (Dhamodhar et al., 2012).

Hasan et al., (2014) have used quercitrin in combination with deoxynojirimycin is synergistic across the range of cariogenic mechanisms of S.mutans compared to their individual effect combination to suppress the cariogenic pathways of $S$. mutans but negative results of inhibition of S.mutans still aroused. One of the recent investigation showed the (MDR) Multidrug resistant species of S.mutans can thrive at any fluctuating conditions and different concentrations of growth parameters like $p \mathrm{H}$, Temperature and $\mathrm{NaCl}$ tolerance in oral cavity and exhibited the resistance ability of S.mutans against all natural stipulations of oral crater of human beings (Karikalan and Mohankumar, 2016a).

$\mathrm{R}$-plasmid is a conjugative factor in bacterial cells that promotes resistance to agents such as antibiotics, metal ions, ultraviolet radiation, and bacteriophage. Another group was resistance $(\mathrm{R})$ plasmids which carry that encode resistance to antibiotics. It was an R-plas- mid (pSC101) that proved instrumental to the generation of the first recombinant DNA molecule, (Kennath 2008). This study focuses on isolate the R-plasmids from Ampicillin resistant strains of Streptococcus mutans.

\section{MATERIAL AND METHODS}

Extracted tooth samples were collected from endocarditis patients in critical condition from a reputed Hospital. Decayed tooth from the patient was collected with a sterile forceps and emptied into Mitis Salivarius Bacitracin agar, broth-based system (Hi-media, Mumbai) and the extracted samples were placed into the peptone water (Transported media) and it was used as per requirement. The collected samples were plated on Mitis-Salivarius Bacitracin Agar (MSB) and incubated at $37^{\circ} \mathrm{C}$ for overnight to $24 \mathrm{hrs}$. Cultures showing hemolysis on MSB were included in detailed study with potassium tellurite and Bacitracin was the additional chemicals to the MSB media. The stock cultures of the strains were then prepared in Brain-Heart Infusion (BHI) Broth (Hi-Media Laboratories, Mumbai) incubated at $37^{\circ} \mathrm{C}$ for $48-72$ hand stored at $4^{\circ} \mathrm{C}$.

The isolates were identified on the basis of their morphological, physiological and biochemical characteristics. Biochemical tests included, Gram staining, Motility, Catalase test, Voges-proskauer, Haemolysis, Growth at $45^{\circ} \mathrm{C}$, Growth in $6.5 \% \mathrm{NaCl}$ broth, Bile-esculin hydrolysis test, Sensitivity to Bacitracin and Optochin, Hydrogen peroxide production, Carbohydrate fermentation tests Lactose, Mannitol, Sorbitol, Sucrose, Raffinose and Inulin.

The disc diffusion test by Kirby-Bauer was employed to check the antibiotic susceptibility of the isolates (Kirby, et al. 1966). Antibiotics Penicillin-G, Ampicillin, Cefaclor, Tetracycline, Erythromycin, Chloramphenicol, Ciprofloxacin, Amoxicillin, Vancomycin and Kanamycin (Hi-Media Laboratories, Mumbai) were used.

\section{RESULTS AND DISCUSSION}

The collected samples were processed, from 20 - 60 year old male patients and female patients (Table 1). The isolated colonies of Streptococcus mutans on Mitis-Salivarius Bacitracin agar (MSB) were appeared with blue color colonies and suspected colonies of S.mutans were subjected to various biochemical tests (Table 2). The colonies were positively identified as $S$. mutans according to the Bergey's Manual guidelines and comprising the antibiotic susceptibility (Table 3). The isolate obtained was found sensitive to Chloramphenicol (30mcg) and Ciprofloxacin $(5 \mathrm{mcg})$ and conspicuously resistant to Penicillin-G (10mcg), Erythromycin (15mcg), Cefaclor (2mcg), 


\begin{tabular}{|c|c|c|c|}
\hline \multicolumn{4}{|c|}{$\begin{array}{l}\text { Table 1: Sample collection from Caries } \\
\text { patients }\end{array}$} \\
\hline $\begin{array}{l}\text { No of } \\
\text { Patients }\end{array}$ & Gender & Age & Dental caries \\
\hline 30 & Female & $20-60$ & Positive \\
\hline 20 & Male & $21-52$ & Positive \\
\hline
\end{tabular}

\begin{tabular}{|c|c|c|}
\hline S. No & Test Observations & Results \\
\hline 1. & Gram stain & Positive \\
\hline 2. & Motility & Negative \\
\hline 3. & Colony Colour & Dark blue \\
\hline 4. & Indole & Negative \\
\hline 5. & Methyl red & Negative \\
\hline 6. & VP test & Positive \\
\hline 7. & Citrate utilization & Negative \\
\hline 8. & Hemolysis & $\Upsilon$ \\
\hline 9. & Catalase & Negative \\
\hline 10. & Sucrose & Positive \\
\hline 11. & Glucose & Positive \\
\hline 12. & Mannitol & Positive \\
\hline 13. & Sorbitol & Positive \\
\hline 14. & Raffinose & Positive \\
\hline 15. & Melibiose & Positive \\
\hline 16. & Inulin & Positive \\
\hline 17. & Starch & Positive \\
\hline 18. & Urea & Negative \\
\hline
\end{tabular}

Vancomycin (30mcg), Tetracycline (30mcg), Ampicillin (5mcg), Kanamycin (10mcg) and Amoxicillin (30 mcg).

Most of the (100\%) S.mutans isolates were resistant to Ampicillin and (70\%) were Penicillin-G, $(65 \%)$ were
(63\%) Amoxicillin and lowest were (50\%) to Erythromycin. All the 10 isolates of $S$. mutans were found to be multidrug resistant and were resistant to a minimum of 4 antibiotics and maximum of 100\% of isolates were resistant to Ampicillin antibiotic. Sensitivity was observed for the antibiotics Ciprofloxacin, and Chloramphenicol. The isolates showed decreasing sensitivity towards above two antibiotics. While 50\% of the isolates showed intermediate sensitivity to Erythromycin, 50\% showed complete resistance. The isolates were showed complete resistance to Penicillin-G and Ampicillin (Fig. 1). Ciprofloxacin and Chloramphenicol proved to be the most effective antibiotics against S.mutans and this isolate showed the resistant zones against Ampicillin, Amoxicillin and Penicillin-G antibiotics in plates (Fig. 2). Particularly, resistant plasmid of Ampicillin resistant strains, were isolated in this study and out of five isolates of S.mutans only 2-5 isolates (KK2, 3 and KK4, 5) showed plasmids 800bp and 700bp respectively (Fig. 3).

Viridans group Streptococci resistant to antibiotics have increasingly been reported over the past decade, while studies on antibiotic resistance of Streptococcus mutans group are few. Streptococcus mutans, being gram-positive cocci, is expected to be certainly susceptible to cell wall synthesis inhibiting antibiotic like Penicillin, protein synthesis inhibiting antibiotics like Chloramphenicol and tetracycline. But recent studies indicate the emergence of penicillin resistance in Streptococcus mutans, which are generally considered uniformly susceptible to penicillin. In a recent study from the isolates obtained from a hospital, the S.mutans was found to be uniformly resistant to the $\beta$-lactam antibiotic, Penicillin (Jesse Joel et al., 2006). In another recent study, $S$. mutans isolates are multidrug resistant with resistance to Amoxicillin, Pencillin (Fani et al., 2007), resistant against to Ampicillin (Dhamodhar et al., 2012).

\begin{tabular}{|l|l|l|l|l|}
\hline \multicolumn{5}{|l|}{ Table 3: Antibiotic Susceptibility of Streptococcus mutans } \\
\hline S. No & $\begin{array}{l}\text { Antibiotic Used } \\
\text { (Disc) }\end{array}$ & $\begin{array}{l}\text { Concentration of } \\
\text { the disc (mcg) }\end{array}$ & $\begin{array}{l}\text { Zone of } \\
\text { Inhibition }\end{array}$ & Results \\
\hline 1. & Amoxicillin & $30 \mathrm{mcg}$ & $8 \mathrm{~mm}$ & $\mathrm{R}$ \\
\hline 2. & Ampicillin & $5 \mathrm{mcg}$ & $10 \mathrm{~mm}$ & $\mathrm{R}$ \\
\hline 3. & Cefaclor & $2 \mathrm{mcg}$ & $10 \mathrm{~mm}$ & $\mathrm{R}$ \\
\hline 4. & Chloramphenicol & $30 \mathrm{mcg}$ & $21 \mathrm{~mm}$ & $\mathrm{~S}$ \\
\hline 5. & Ciprofloxacin & $5 \mathrm{mcg}$ & $20 \mathrm{~mm}$ & $\mathrm{~S}$ \\
\hline 6. & Erythromycin & $15 \mathrm{mcg}$ & $11 \mathrm{~mm}$ & $\mathrm{R}$ \\
\hline 7. & Kanamycin & $10 \mathrm{mcg}$ & $12 \mathrm{~mm}$ & $\mathrm{R}$ \\
\hline 8. & Penicillin-G & $10 \mathrm{mcg}$ & $9 \mathrm{~mm}$ & $\mathrm{R}$ \\
\hline 9. & Tetracycline & $30 \mathrm{mcg}$ & $19 \mathrm{~mm}$ & $\mathrm{R}$ \\
\hline 10. & Vancomycin & $30 \mathrm{mcg}$ & $13 \mathrm{~mm}$ & $\mathrm{R}$ \\
\hline & & & & \\
\hline
\end{tabular}




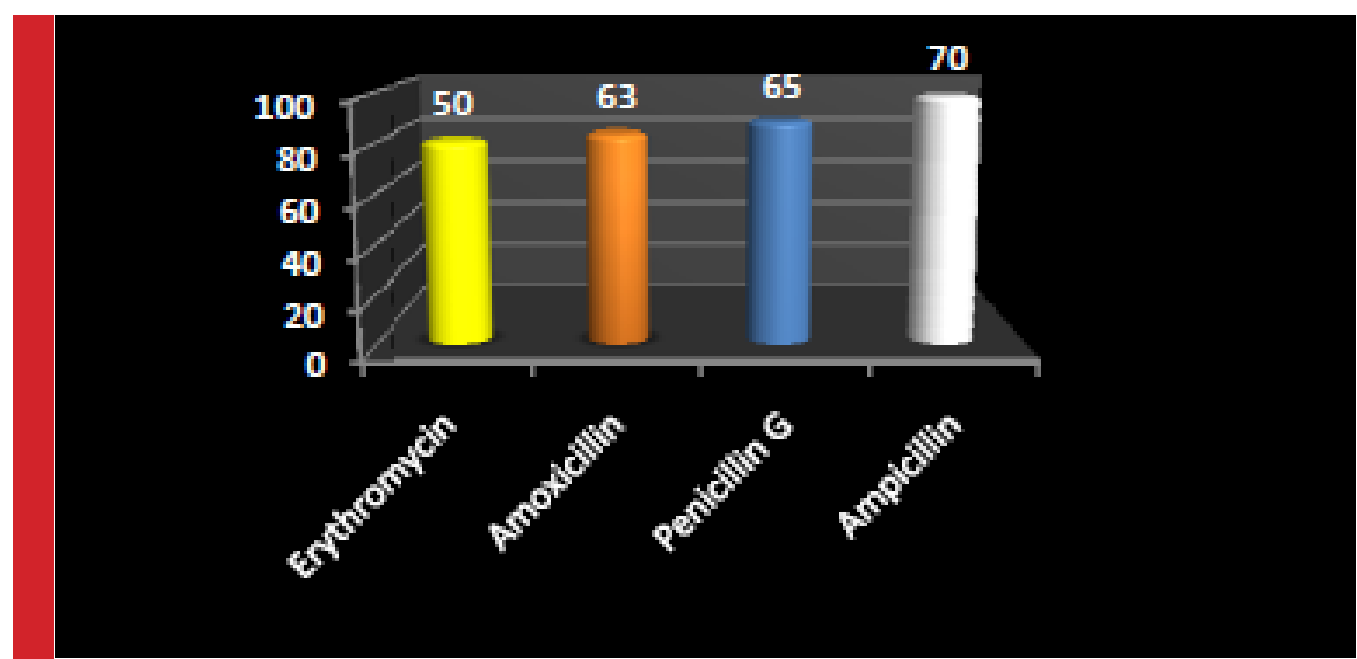

FIGURE 1: Antibiotics showed resistant to all the tested strains

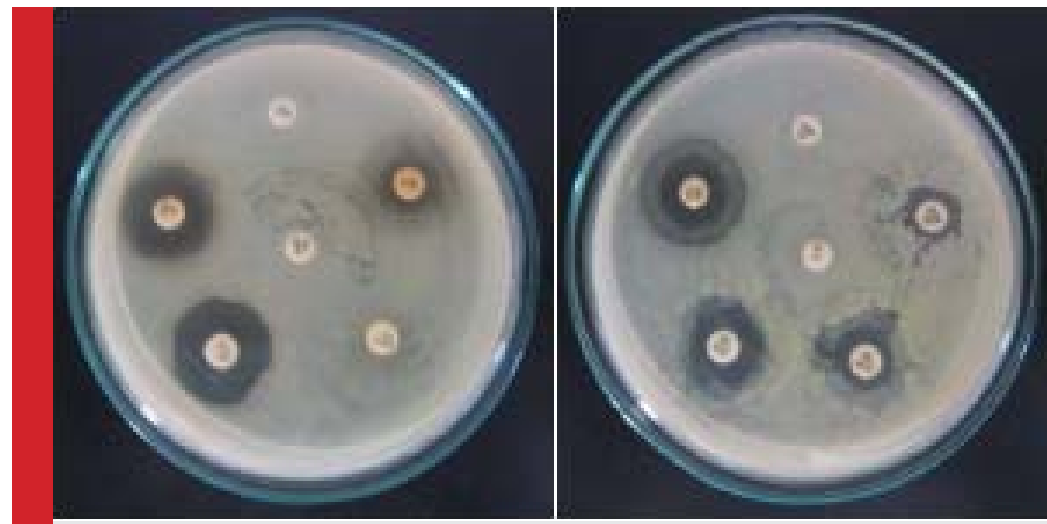

FIGURE 2: Ampicillin, Amoxicillin and Penicillin antibiotics showed resistance

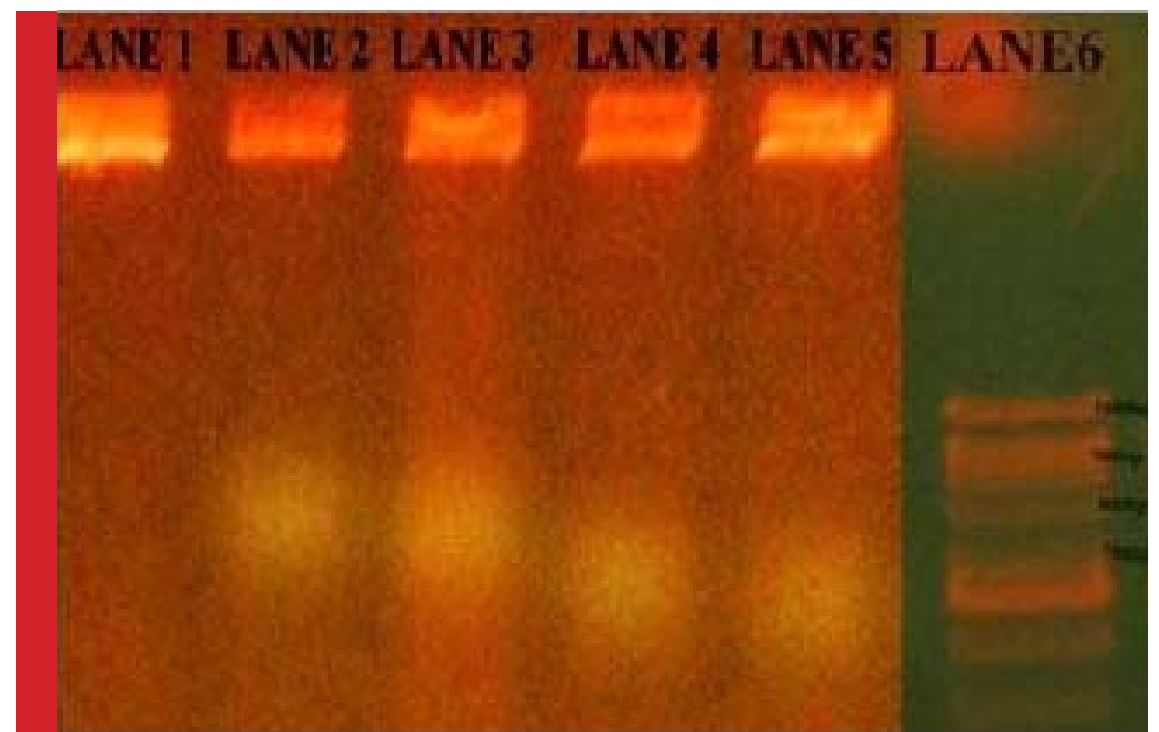

FIGURE 3: Migration of plasmid DNA fragments in agarose gel electrophoresis $(0.7 \%)$ at 50 volts and Lane 1 to $5-S$. mutans strains and Lane 6 -DNA molecular marker $(1 \mathrm{~kb})$. 
A highly resistant percentage of $80 \%$ to ciprofloxacin observed against S. mutans isolates (Gamal, 2014). Two important antibiotics were showed the 50\% by Amoxicillin and Ciprofloxacin resistant against S.mutans isolates were documented (Karikalan and Mohankumar, 2016). 80\% of the recovered isolates exhibited the sensitive activity against Amoxicillin, Ampicillin, Chloramphenicol, Erythromycin, Penicillin, Clindamycin, Tetracycline, and resistant activity against Ciprofloxacin against Streptocoocus spp (Devi et al., 2011) and these reports differed from this study.

This antibiotic is routinely prescribed as prophylaxis to the patients prior to massive dental procedures. It has been reported that the introduction of penicillin in the prophylactic treatment has reduced the infection, but the long-term use of penicillin could be compromised by the emergence of resistant strains (Fani et al., 2007). Erythromycin and Clindamycin have been recommended as alternative options for patients who are allergic to penicillin and are also widely used for antibiotic prophylaxis of endocarditis associated with dental procedures (Bagg, 1999). It may also be recommended that amoxicillin and penicillin $\mathrm{G}$ are the most effective antibacterial drugs for the treatment of dental caries (Devi et al., 2011).

A new recent study proved that $50 \%$ of resistant was observed in 6 antibiotics among 14 antibiotics, above, particularly Penicillin, Ceftriaxone, Cephipime, Cephotaxime, Ampicillin and Cefaclor and these drugs were prescribed in clinical trials against dental practices (Karikalan and Mohankumar, 2016 b, c).But in this study antibiotics totally varied and totally resistance to all the $S$. mutans isolates from above study. These antibiotics have developed resistance against the strains of $S$. mutans as revealed by the zone of inhibition in the present study.

Thus the present study revealed the emergence of multi drug resistance in Streptococcus mutans in the urban Tirupur region, which has actually not only made general prophylaxis a very cumbersome affair but also has further intricated the antibiotic resistance pattern of this region.

The presence of plasmids in the dental caries bacterial isolates was determined using a modification of boiling preparation method (Holmes and Quigley, 1981). Plasmid DNA was separated by electrophoresis on a $0.7 \%$ agarose gel $(\mathrm{w} / \mathrm{v})$ at 50 volts overnight. The gel was stained with Ethidium-bromide, visualized under UV transillumination and photographed.

Only Ampicillin resistant strains are selected to isolate the R-plasmids from caries strains. Finally, Ampicillin resistant strains showed the R-plasmids. An important work was done here that caries patient has multi drug resistant bacterial strains. Particularly, resistant plasmid of Ampicillin resistant strains, were isolated in this study.

\section{CONCLUSION}

Only 50 dental caries culture samples were obtained and processed. Out of 50 patients aged from 20-60 and 50 dental caries of 50 patients were found positive for the pathogen Streptococcus mutans thus, implicating it yet again exclusively as the etiological agent of dental caries. Among the total 50 isolates, only 10 were conclusive as S.mutans and when checked for antibiotic susceptibility it was found to show Multiple Antibiotic Resistance (MAR) to all the other antibiotics. In the present study, the emergence of multi drug resistance in $S$. mutans was observed. This suggests the need for a regular surveillance program to control and manage the antibiotic resistance in these bacteria. It was concluded that, at least in this region of India, S. mutans has become an important matter of concern because of its higher preponderance of isolation and emergence of drug resistance. Based on the results obtained, this study deals with identifying the particular antibiotic resistance containing R-plasmids for treatment of dental caries.

\section{ACKNOWLEDGEMENT}

The authors wish to thank Dr. K. Shunmugasundharam, Principal, Chikkanna Government Arts College, and Tirupur for providing facilities to conduct the entire research investigation.

\section{REFERENCES}

Ash, M.M., Ward, M.L., Arbor and Ash A.K. (1986). Oral Pathology An introduction to general and oral pathology for hygienist. Philadelphia: Lea and Fibiger Publishers. 144-233.

Bagg, J. (1999). Essentials of microbiology for dental students. Oxford University Press. New York. 1-326.

Da Silva, A.C.B., Da Silva, D.R., De Macêdo Ferreira, S.A., Agripino, G.G., Albuquerque, A.R., and Do Rêgo, T.G. (2014). In Silico Approach for the Identification of Potential Targets and Specific Antimicrobials for Streptococcus mutans. Advances in Bioscience and Biotechnology. 5; 373-385.

Devi, A., Singh, V. and Bhatt A.B. (2011) Antibiotic sensitivity pattern of Streptococcus against commercially available drugs and comparison with extract of Punica granatum. International Journal of Pharma and Bio Sciences. 2(2):504-508.

Dhamodhar, P., Murthy, S., Channarayappa, Karthik, R., Neha, G., Shanthakumar, S.S. and George, J. V. (2012). Antibacterial efficacy of Syzygium aromaticum extracts on multi-drug resistant Streptococcus mutans isolated from dental plaque samples. J Biochem Tech. 3(5):155-157. 
Fani, M.M., Kohanteb J. and Dayaghi, M. (2007). Inhibitory activity of garlic (Allium sativum) extract on multidrugresistant Streptococcus mutans. J. Indian Soc. Pedod. Prev Dent. 25:164-168.

Gamal, M.E. (2014). Control of growth Streptococcus mutans isolated from saliva and dental caries. Int.J.Curr.Microbiol. App.Sci. 3(10); 1-10.

Hasan, S., Singh, K., Danisuddin, M., Verma, P.K., and Khan, A.U. (2014). Inhibition of major virulence pathways of Streptococcus mutans by quercitrin and deoxynojirimycin: A synergistic approach of infection control. PLoS One, 9(3): e91736. doi: 10.1371/journal.pone.0091736.

Holmes, D.S. and Quigley, M. (1981). A rapid boiling method for the preparation of bacterial plasmids. Anal. Biochem. 114:193197.

Joel, T.J. and Ramteke, P.W. [2006]. Extracellular Polysaccharide Produced by Multi-Drug Resistant Streptococcus mutans Isolated from Sub-acute Endocarditis Patients - A Hospital Study.

Karikalan, S., and Mohankumar, A. (2016a). Antibiogram of Streptococcus mutans isolated from dental caries patients. International Journal of Medical and Health Research. 2(3); 79-83.

Karikalan, S., and Mohankumar, A. (2016b). Manifestation of sodium fluoride resistant pathogen isolated from tooth decay samples. International Journal of Biology Research. 1(1); 3335.

Karikalan, S., and Mohankumar, A. (2016c). Optimization of growth parameters on multi drug resistant Streptococcus mutans. International Journal of Biology Research. 1(1); 36-39.

Kenneth, T. (2015). http://www.Text book of bacteriology.net/ author Kenneth Dodar (accessed on; 30/06/08).

Kirby, W.M., Bauer, A.W., Sherris, J.C. and Turck, M. (1966). Antibiotic susceptibility testing by a standardized single disk method. Am J Clin Pathol. 45(4); 493-496.

Loesche, W.J. (1986). Microbiology of dental decay and periodontal disease. In: Baron S. T Albrecht, Castro G Baron's Medical Microbiology. Galveston. Texas: University of Texas Medical Branch. 1169-1170.

Patterson, M.J. (1996) Viridians Streptococci can cause endocarditis. In: Baron S, Albrecht T, Castro G, editors. Baron's Medical Microbiology. Galveston, Texas: University of Texas Medical Branch. 199-212.

Ryan, K.J. and Ray, C.G. (2004). Sherris JC. Sherris Medical Microbiology. An introduction to infectious diseases. 4th edn. New York: McGraw-Hill.

Wagman, R.J. (2000). The teeth and gums In: The New Complete Medical and Health Encyclopedia vol. III. Chicago: Ferguson Publishing Company 719-740. 